\title{
TITLE:
}

\section{A new process for catalyst-free production of biodiesel using supercritical methyl acetate}

\section{AUTHOR(S):}

Isayama, Yohei; Saka, Shiro

\section{CITATION:}

Isayama, Yohei ...[et al]. A new process for catalyst-free production of biodiesel using supercritical methyl acetate. Fuel 2009, 88(7): 1307-1313

\section{ISSUE DATE:}

2009-07

URL:

http://hdl.handle.net/2433/87777

\section{RIGHT:}

c 2009 Elsevier Ltd. All rights reserved; This is not the published version. Please cite only the published version.; この論文は出版社版でありませ ん。引用の際には出版社版をご確認ご利用ください。 


\title{
A New Process for Catalyst-Free Production of Biodiesel Using Supercritical Methyl Acetate
}

Shiro Saka* and Yohei Isayama

Department of Socio-Environmental Energy Science, Graduate School of Energy Science, Kyoto University, Yoshida-honmachi, Sakyo-ku, Kyoto 606-8501, Japan

\begin{abstract}
Production of glycerol is unavoidable in the conventional processes for biodiesel fuel (BDF) production. In this research, therefore, we investigated conversion of rapeseed oil to fatty acid methyl esters (FAME) and triacetin by processing of supercritical methyl acetate. As a result, it was discovered that the trans-esterification reaction of triglycerides with methyl acetate can proceed without catalyst under supercritical conditions, generating FAME and triacetin. In order to study the effect of the triacetin addition to FAME, its effect was investigated on various fuel characteristics. It was, consequently, discovered that there were no adverse effects on the main fuel characteristics when the molar ratio of methyl oleate to triacetin was 3:1, corresponding to the theoretically derived mole ratio from the trans-esterification reaction of rapeseed oil with methyl acetate. Moreover, the addition of triacetin to methyl oleate improved the pour point and triacetin has high oxidation stability. Therefore, by defining BDF as a mixture of methyl oleate with triacetin, we can obtain an improved yield of $105 \%$ of BDF by the supercritical methyl acetate, in excess of the yield of the conventional process.
\end{abstract}

Keywords: Biodiesel; Supercritical catalyst-free process; Methyl acetate; Fatty acid methyl ester; Triacetin 


\section{Introduction}

Biodiesel fuel (BDF), which is an alternative of the diesel derived from oils and fats, has been recently receiving an intensive attention, and in the currently used alkaline catalyst method, triglycerides (TG) are trans-esterified in the presence of an alkaline catalyst with methanol and converted to fatty acid methyl esters (FAME). Therefore, what is referred to as BDF is in fact a mixture of various fatty acid methyl esters.

Although the alkaline catalyst method has the benefit of using moderate reaction conditions, several aqueous washings are needed to remove the catalyst after the reaction. Moreover, the oils and fats used may contain water and free fatty acids. The presence of water reduces the catalytic activity, while free fatty acids react with the catalyst to produce saponified products, risking a reduction in the yield of FAME. Therefore, manufacturing BDF from waste cooking oils by the alkaline catalyst method is not necessarily easy $[1,2]$.

Non-catalytic BDF production methods with supercritical methanol have been, therefore, developed in order to resolve the various problems in these techniques [3]. In one of these methods, the one-step supercritical methanol method (Saka Process), the trans-esterification reaction of TG without catalysts proceeds to produce FAME and glycerol by processing the raw oils and fats using supercritical methanol. FAME are also generated simultaneously by the esterification reaction of the free fatty acids [4], such that even if there is a high content of free fatty acids in the raw material oils and fats, FAME can be derived at a high yield, and no saponified products are produced. Moreover, the separation and purification are easy because of the non-catalytic process. Unlike the alkaline catalyst method, it can also be adapted to relatively long chain alcohols [5]. However, this method requires extreme temperature and pressure conditions of $350^{\circ} \mathrm{C}$ and $43 \mathrm{MPa}$, respectively, and induces breakdown of unsaturated fatty acids and trans isomerization, leading to adverse effects on the fluidity of the fuel at low temperatures [6, 7]. Thus, Cao et al reported that oils and fats can be converted into FAME successfully at lower temperature by supercritical methanol with co-solvent such as propane [8]. Furthermore, $\mathrm{CO}_{2}$ addition to supercritical methanol can make the reaction temperature lower [9]. 
Kusdiana and Saka developed the two-step supercritical methanol method (Saka-Dadan Process) as a BDF manufacturing process at very mild reaction conditions [10]. In this method, the hydrolysis reaction of the triglycerides is induced by subcritical aqueous processing and thus the triglycerides are converted to fatty acids and glycerol. After the reaction mixture is left undisturbed, the oil layer containing the fatty acids and the aqueous layer containing the glycerol are separated. Methanol is, then, added to fatty acids in the oil fraction which are transferred into FAME by the esterification reaction under supercritical condition. Because the reaction conditions in this method are relatively mild $\left(270^{\circ} \mathrm{C}\right.$ and $\left.7 \mathrm{MPa}\right)$, no breakdown of unsaturated fatty acids or other changes are barely induced [6]. Therefore, the two-step method (Saka and Dadan Process) is more suitable for practical application, compared with the one-step method.

In the processes using the method mentioned above, the production of glycerol as a by-product could not be avoided. Therefore, with the production of BDF increased in the recent years, glycerol has been overproduced. However, in the alkaline catalyst method, the glycerol was recovered as along with a mixture of methanol, water, and alkaline catalyst. To produce pure glycerol, crude glycerol must be neutralized by acid such as sulfuric acid and this process forms a large quantity of salt. Thus, purification of crude glycerol is very complicated and needs much cost. The sales value of this crude glycerol becomes extremely low at approximately $\$ 0.1 / \mathrm{kg}$ when compared with the value of purified glycerol, at approximately $\$ 1.3 \sim 2.0 / \mathrm{kg}$. When the cost of transportation is taken into consideration, the market price is in fact uneconomical [11].

For the future, the production of glycerol after BDF manufacturing is expected to increase, unless an effective method is established. Fabbri et al have, therefore, proposed that oils and fats can be reacted with dimethylcarbonate in the presence of alkalis as catalysts to produce FAME and cyclic glycerol carbonate esters of fatty acids (FAGC), which can be utilized as BDF [12]. Although this method will not produce glycerol as a by-product, it utilizes the alkaline catalyst, which is difficult to be adapted for some waste oils and fats.

In this research, therefore, we focused on one of the trans-esterification reactions. Xu et al have 
already reported the reaction by enzyme [13], but enzymatic reaction takes long time to convert oil and fats into FAME completely. Thus, we propose a non-catalytic BDF manufacturing process by using supercritical methyl acetate, investigating the reactivity of rapeseed oil with methyl acetate. Moreover, the characteristics of the fuel produced by mixing FAME and triacetin were evaluated to establish if its mixture is usable as BDF.

\section{Materials and Methods}

\subsection{Materials}

Rapeseed oil was used for the supercritical treatment of oil and fats, while oleic acid was used as the fatty acid (both manufactured by NACALAI TESQUE INC.), and methyl acetate was used as the reaction solvent $\left(\mathrm{Tc}=234^{\circ} \mathrm{C}\right.$; Pc $\left.=4.69 \mathrm{MPa}[14]\right)$ (manufactured by NACALAI TESQUE INC., 99\%). Moreover, triolein was used as the standard for triglycerides and methyl oleate as that for FAME (both manufactured by Sigma-Aldrich, $\geq 99 \%$ ), while triacetin as that for the final product (manufactured by NACALAI TESQUE INC., 98\%).

As the standard products for monoacetyl diglyceride and diacetyl monoglyceride, excess of acetic anhydride (manufactured by NACALAI TESQUE INC., 97\%) and pyridine (manufactured by NACALAI TESQUE INC., 99.5\%) were added to 1,3-diolein and 1-oleiyl-rac-glycerol (both manufactured by Sigma-Aldrich, 99.5\%), respectively, and after reacting overnight, the solvent was removed using an evaporator to produce 1,3-dioleyl-2-acetyl-glycerol and 1-oleyl-2,3-diacetyl-glycerol.

\subsection{Supercritical treatment with methyl acetate}

For the supercritical methyl acetate processing of rapeseed oil and oleic acid, a flow-type supercritical fluid conversion system was used. The raw material of rapeseed oil, and solvents were delivered by a high pressure pump from the raw material tanks in this system, and after mixing in the reaction tube orifice, they were led into the reaction tube in a salt bath (volume: $288 \mathrm{~mL}$, material: Hastelloy C276), while maintaining a specific temperature, to perform the supercritical processing. At this instance, 
the processing time was controlled by the flow volume setting of the high-pressure pump, while the pressure was controlled by adjusting the back-pressure regulator. After the processing in the reaction vessel, the reaction was stopped using a cooler and the processed product was recovered.

The supercritical processing conditions in this research were set at temperatures of $270-380^{\circ} \mathrm{C}$ and 20MPa pressure, with processing times ranging from 10 to $120 \mathrm{~min}$. Moreover, the molar ratio of rapeseed oil to methyl acetate was 1:42 (volumetric ratio of 1:3.4), the molar ratio of oleic acid and methyl acetate was 1:14 (volumetric ratio of 1:3.5).

\subsection{Analysis of FAME and triacetin}

After supercritical processing with methyl acetate, the solvent was removed from the products using a rotary evaporator to obtain the BDF. The obtained BDF was, then, analyzed by gel permeation chromatography (GPC) (Column: GF-310HQ, oven temperature: $40^{\circ} \mathrm{C}$, flow speed: $1 \mathrm{~mL} / \mathrm{min}$, mobile phase: acetone, detector: RID). For the calibration of the curve of the standard products, triolein, 1-oleyl-2,3-diacetyl-glycerol, 1,3-dioleyl-2-acetyl-glycerol, methyl oleate, and triacetin were used.

\subsection{Yields of FAME and BDF}

The yield of FAME from supercritical processing with methyl acetate of rapeseed oil was calculated from the area of the peak in the GPC chromatogram with a value of 100 for the assumed theoretical maximum concentration. Moreover, apart from that, with a view to using the combined FAME and triacetin, generated by supercritical processing of rapeseed oil with methyl acetate, as BDF, the combined weight of FAME and triacetin generated per unit weight of triglycerides was used to define the BDF yield $\left(\mathrm{Y}_{\mathrm{BDF}}\right)$, and was calculated from the peak area in the GPC chromatograph. According to the calculation, the maximum theoretical value for BDF recovery was $125 \%$.

\subsection{Mathematical model}

The reaction formula for the trans-esterification reaction of triglicerides and methyl acetate is as 
shown in Equation 1; however, in reality, the reaction proceeds through three stages.

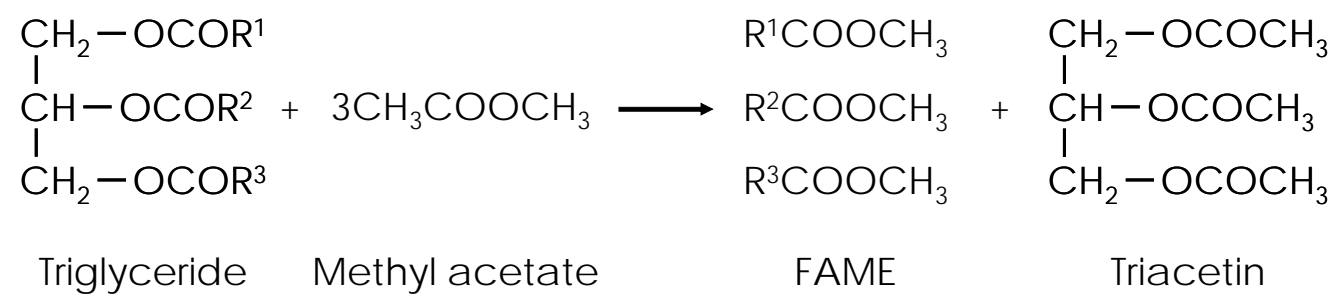

First, triglyceride and methyl acetate react, one molecule at a time, to generate one molecule each of monoacetylglyceride and FAME. In the same manner, diacetylglyceride and FAME are generated from monoacetylglyceride and methyl acetate, and triacetin and FAME are generated from diacetylglyceride and methyl acetate. In fact, because there is some generation of the reverse reaction, for the purposes of a strict theoretical analysis of reaction rate constant, six reaction rate constants must be used. However, in this research, because excess methyl acetate was added in respect of triglyceride, it was assumed as a pseudo first-order reaction, and to simplify the performance analysis of model, Equation 2 was used.

$$
\frac{d[T G]}{d t}=-k_{I E}[T G]
$$

where [TG] is the molar concentration (mol\%) of triglyceride and $\mathrm{k}_{\mathrm{IE}}$ is the reaction rate constant $\left(\mathrm{sec}^{-1}\right)$. In Equation 3, which is derived from Equation 2, $\mathrm{k}_{\mathrm{IE}}$ was evaluated by deriving the regression curve. The regression curve was constructed by the Levenberg-Marquardt method.

$$
[T G]=e^{-k_{I E} t}[T G]_{0}
$$

The esterification reaction of fatty acids and methyl acetate, as shown in Equation 4, generates one molecule each of FAME and acetic acid from one molecule each of fatty acid and methyl acetate.

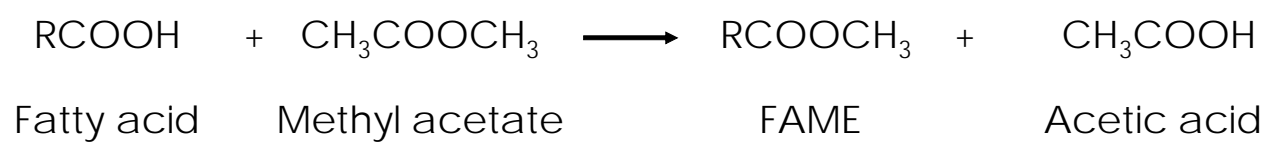

In the esterification reaction of fatty acids and methanol, while the autocatalysis of fatty acid model is appropriate [15], when the reaction uses methyl acetate, each molecule of fatty acid produces one 
molecule of acetic acid. Therefore, the catalytic effect of fatty acids and acetic acids should be considered; however, in this research, it was assumed that the difference can be ignored, and the acid catalytic effect was assumed to be proportional to the aggregate of the molar concentration of fatty acids and acetic acid. In such a case, the reaction rate equation considering the reverse reaction is expressed by Equation 5 .

$$
\frac{d[F A M E]}{d t}=\left(k_{E}[F A][M A]-k_{E}^{\prime}[F A M E][A A]\right) \times([F A]+[A A])
$$

where MA is methyl acetate and AA is acetic acid, $\mathrm{k}$ and $\mathrm{k}^{\prime}$ are the reaction rate constants $\left(\mathrm{sec}^{-1}\right)$ of the reaction and reverse reaction, respectively. Using this equation, the yield changes of each constituent are calculated by the difference method, and by performing the fit using the experimental values, the reaction rate constant can be determined.

\subsection{Measurement of fuel properties of model BDF}

Using methyl oleate (manufactured by NACALAI TESQUE INC.) as the FAME and any mixture proportion with triacetin, the kinematic viscosity, pour point, and cold filter plugging point as well as oxidation stability were measured. In particular, the model BDF was defined as a 3:1 molar ratio of methyl oleate and triacetin (approximately 4:1 on a wt\% basis), and density, flash point, cetane number, and 100\% residual carbon fraction were measured, in addition to the values above.

The kinematic viscosity was measured using the automatic kinematic viscosity test apparatus AKV-201, the pour point using the automatic pour point and cloud point test apparatus MPC-102L, the cold filter plugging point using the automatic cold-filter plugging-point test apparatus AFP-102, the flash point using the Pensky-Martens closed-cup flash point measurement apparatus APM-7, and the $100 \%$ residual carbon fraction using the micro-residue carbon-fraction measurement apparatus ACR-M3 (all manufactured by Tanaka Kagaku Kiki) by the methods specified in the Japanese Industrial Standards JISK2283, ASTM D6749, JIS K2288, JIS K2265, JIS K2270, respectively.

Moreover, the oxidation stability was measured using the Rancimat test apparatus (manufactured by Metrohm) based on EN14112, and the density was measured using the I-type floating density test 
method specified in JIS K2249. Moreover, the cetane number was measured in accordance with IP541/06 using the fuel test device FIA-100 (manufactured by Fuel Tech).

\section{Results and Discussion}

\subsection{Trans-esterification of triglycerides with methyl acetate}

Figure 1 shows the FAME yield and recovered amount of BDF when rapeseed oil was supercritically processed with methyl acetate. The dotted line shows BDF as FAME only, while the solid line shows BDF as the aggregate of FAME and triacetin. At a reaction temperature greater than $320^{\circ} \mathrm{C}$, FAME is generated from the oil and methyl acetate, and trans-esterification reaction proceeds as shown in Equation 1. Therefore, it is clear that the trans-esterification reaction of triglicerides with methyl acetate proceeds under supercritical conditions without catalyst.

While a 97\% yield of FAME can be derived after processing for 45 min at $350^{\circ} \mathrm{C}$, the yield declines thereafter. In contrast, a relatively high yield of FAME of $76 \mathrm{wt} \%$ can be obtained after $15 \mathrm{~min}$ of processing at the highest temperature of $380^{\circ} \mathrm{C}$, thereafter the rise in yield levels off and maximizes at 86 wt $\%$ after $45 \mathrm{~min}$. On the other hand, with processing at $300^{\circ} \mathrm{C}$, any FAME is hardly produced after 60 min of processing.

Meanwhile, the $\mathrm{BDF}$ recovery after $45 \mathrm{~min}$ of processing at $350^{\circ} \mathrm{C}$ reached $105 \mathrm{wt} \%$, which is far exceeding the FAME-only BDF recovery of $97 \mathrm{wt} \%$. The theoretical maximum recovery of $125 \mathrm{wt} \%$ was not reached but the recovery rate of $105 \%$ is greater than the maximum BDF recovery value of $100 \%$ when BDF is measured as the conventional FAME only. Therefore, when the mixture of FAME and triacetin derived in this process is used as BDF, more BDF can be derived from a unit amount of rapeseed oil.

Imahara et al reported that the breakdown of polyunsaturated fatty acids such as linolenic acid is remarkable in temperature higher than $300^{\circ} \mathrm{C}$ [7]. Therefore, it is presumed that the less yield of FAME at $380^{\circ} \mathrm{C}$ compared with $350^{\circ} \mathrm{C}$ is due to the breakdown of unsaturated fatty acids at the higher temperature. It is assumed that a similar reason applies for the lower yield after 60 min treatment at $350^{\circ} \mathrm{C}$ compared with 
$45 \mathrm{~min}$. On the other hand, at $300^{\circ} \mathrm{C}$ the reaction hardly proceeded in spite of the fact that an $80 \mathrm{wt} \%$ yield of FAME resulted only after 2min treatment with methanol, reported by Kusdiana and Saka [16]. Therefore, the reaction rate constant with methyl acetate must be very low at the lower temperature.

\subsection{Esterification of fatty acids with methyl acetate}

The FAME yield after supercritical processing of oleic acid with methyl acetate is shown in Fig. 2. Methyl oleate is derived from the esterification reaction and the FAME yield reached $91 \mathrm{wt} \%$ after 20 min of processing at $350^{\circ} \mathrm{C}$. Meanwhile, when the processing temperature was $270^{\circ} \mathrm{C}$, the FAME yield was as low as $30 \mathrm{wt} \%$ even after 120 min of processing. However, a FAME yield higher than $90 \mathrm{wt} \%$ could be achieved after $60 \mathrm{~min}$ at $320^{\circ} \mathrm{C}$ and $120 \mathrm{~min}$ at $300^{\circ} \mathrm{C}$.

It is clear from these results that the esterification reaction of oleic acid with methyl acetate proceeds under supercritical conditions. In this reaction, over $90 \mathrm{wt} \%$ FAME yield can be obtained even with processing at $300^{\circ} \mathrm{C}$, showing that the reactivity is better than in the trans-esterification reaction in Fig. 1. This may be because the starting material oleic acid and/or the acetic acid produced is providing acid catalysis. Therefore, this suggests that in order to produce a high-grade BDF, the use of methyl acetate as the esterification solvent media results in a lower temperature manufacturing method.

\subsection{Kinetics in trans-esterification and esterification}

An Arrhenius plot of the reaction rate constant for the esterification reaction of oleic acid and the trans-esterification reaction of the rapeseed oil using supercritical processing with methyl acetate is shown in Fig. 3. The results of the esterification reaction and trans-esterification reaction using methanol are also shown with the broken line, just for comparison [16, 17]. On comparing methyl acetate and methanol in the trans-esterification reaction for the triglycerides (TG), the methanol has higher reactivity in all the temperature ranges. Moreover, in the case of methanol, the tendency for the reaction rate constant to rise dramatically at $270^{\circ} \mathrm{C}$ to $300^{\circ} \mathrm{C}$ has been noted, but no such tendency was observed with methyl acetate.

Kusdiana and Saka have explained this phenomenon from the perspective of mutual solubility of 
methanol and the oil [16]. In other words, at lower temperatures, because the solubility of triglycerides in methanol presents a two-phase reaction, the reaction rate constant is low. At higher temperatures, a cleavage of the hydrogen bonding among the methanol molecules results in the mutual solution between the hydrophobic triglycerides and methanol molecules, presenting a single-phase reaction site, and the reactivity is greatly enhanced by the improvement in the solubility. In contrast, the mutual solubility of triglycerides and methyl acetate is relatively high and presents a single phase reaction site at room temperature. It is, therefore, considered that the rise in reaction rate constant shown by methanol could not be seen. From these results, it is very difficult to produce a high yield below $300^{\circ} \mathrm{C}$ where the breakdown of unsaturated fatty acids can be controlled. This is because the reactivity of methyl acetate with triglycerides is lower than the case with methanol, when BDF is manufactured by non-catalytic trans-esterification,

Moreover, in the esterification reaction of oleic acid as described by FA in Fig. 3 with methyl acetate at $270^{\circ} \mathrm{C}$, the reaction rate constant was $k_{E}=7.0 \times 10^{-5} \mathrm{sec}^{-1}$, which is lower than that of $k_{E}=2.9 \times$ $10^{-3} \mathrm{~s}^{-1}$ achieved with methanol at the same temperature [14]. Therefore, it is evident that the reactivity obtained using methyl acetate is inferior to that achieved using methanol. However, because the value at the relatively lower temperature of $300^{\circ} \mathrm{C}$ is $k_{E}=6.0 \times 10^{-3} \mathrm{sec}^{-1}$ for esterification of oleic acid, the FAME production from fatty acids can be possibly made by supercritical methyl acetate.

\subsection{Effects of blending triacetin with fatty acid methyl esters on fuel properties}

\subsubsection{Kinematic viscosity}

The kinematic viscosity against the concentration of triacetin (TA) in the mixture is shown in Fig. 4a. When the triacetin concentration is $0 \mathrm{wt} \%$, in other words, when only methyl oleate is present, the kinematic viscosity is $4.4 \mathrm{~mm}^{2} / \mathrm{s}\left(40^{\circ} \mathrm{C}\right)$, a value which is almost the same as the value found in the literature [18]. When there exists more than $20 \mathrm{wt} \%$ of triacetin in the mixture, as the concentration of triacetin rises, the kinematic viscosity also rises remarkably, and when there exists only triacetin, it registers a high value of $7.3 \mathrm{~mm}^{2} / \mathrm{s}$. Meanwhile, when the concentration of triacetin in the mixture is lower than 20 wt\%, its effects on the kinematic viscosity are hardly noticeable. Moreover, the kinematic viscosity of the 
model BDF when the molar ratio of methyl oleate to triacetin is 3:1 (weight ratio of $4: 1$, which is $20 \mathrm{wt} \%$ of triacetin in Fig. 4) is $4.5 \mathrm{~mm}^{2} / \mathrm{s}$, well within the viscosity range determined as the Kyoto Standard and EU Standard $\left(3.5-5 \mathrm{~mm}^{2} / \mathrm{s}\right)$.

The kinematic viscosity, defined as the dynamic viscosity of the material divided by its density, is an index expressing the stickiness of a fuel. When the kinematic viscosity rises very high, it prevents the nebulization of the fuel in the ignition chamber, and when very low, it results in reduction of the lubrication effect, hence it must be kept within a regulated range. In a process producing glycerol as a by-product, when there exists glycerol in the BDF or when glycerides are included in reaction intermediates, the glycerides are the main cause of increased kinematic viscosity. In this respect, in a process where triacetin is produced as a by-product, the effect of triacetin is considered to be small on the kinematic viscosity of the mixture. Moreover, it is predicted that the effect of the monoacetylglyceride and diacetylglyceride as the reaction intermediates on increasing the kinematic viscosity is small, compared with the process using methanol.

\subsubsection{Pour point}

Fig. 4b shows the relationship of the triacetin (TA) concentration and pour point in the mixture. The pour point of methyl oleate is $-16^{\circ} \mathrm{C}$, and when triacetin is added, the value remains constant until its concentration reaches approximately $80 \mathrm{wt} \%$. However, in the triacetin concentration range of 80-90 wt\%, the pour point drops extremely rapidly and, e.g., exhibits the low value of $-39^{\circ} \mathrm{C}$ when it is $91 \mathrm{wt} \%$. Moreover, the pour point of triacetin on its own is almost the same as this value at $-40^{\circ} \mathrm{C}$. With regard to this measurement, as shown in the figure, the pour point at any of the concentrations satisfies the value of the Kyoto Standard $\left(\leq-7.5^{\circ} \mathrm{C}\right)$.

The pour point is one index showing the low-temperature fluidity, indicating the temperature at which a fuel congeals and stops flowing under its own weight when the temperature drops. Therefore, fuels with high pour points are not suited for use in winter in cold regions. Thus, the standard value is defined in the Kyoto Standard and elsewhere. 
In this research, it is assumed that the sudden changes in the pour point in the $80-90 \mathrm{wt} \%$ triacetin concentrations were caused by the gradual cooling of the material used in the pour point measurement from the outside, because of which the constituents with high melting point collected and solidified on the outside. In other words, while in the measurement of the pour point, the material is maintained at a temperature and inclined to observe if it flows or not. In the case of a mixture of methyl oleate (m.p. $\left.-18.9^{\circ} \mathrm{C}[19]\right)$ and triacetin (m.p. $-78^{\circ} \mathrm{C}$ [20]), the methyl oleate tends to accumulate on the outside and solidify in advance, as the temperature drops.

At this point, when the methyl oleate concentration is high, it does not pour even if the triacetin has not solidified, because the solidified methyl oleate layer is thick. However, when the methyl oleate concentration is lower in the mixture, the flow of the material is not impeded, if the earlier solidifying layer is less than a certain thickness. This is presumed to be the reason for observing an abrupt change in the pour point with triacetin concentrations in the $80-90 \mathrm{wt} \%$ range. Therefore, it was concluded that in triacetin mixtures, the concentration of triacetin has almost no effect on the pour point, except at high concentrations where a lowering effect is observed.

\subsubsection{Cold filter plugging point}

Figure 4c shows changes in the cold filter plugging point when the triacetin concentration in the mixture is changed. The cold filter plugging point of methyl oleate is $-16^{\circ} \mathrm{C}$ and this value hardly changes until the triacetin concentration reaches approximately $20 \mathrm{wt} \%$. Thereafter, as the triacetin concentration rises, the cold filter plugging point also rises and the cold filter plugging point of triacetin on its own is $14^{\circ} \mathrm{C}$.

The cold filter plugging point indicates the temperature at which the crystals separate out in the cooling material clump together and cause blocking of the filter. Therefore, it provides a guideline for the suitability for use in cold regions in winter, and standard values are set in the Kyoto Standard and others. Because the cold filter plugging point, just like the pour point, is also an index showing the low temperature fluidity of a fuel, in many cases, there is a mutual relationship with the pour point [21]. 
In this research, as is clear from Figs. 4 and 5, the pour point and the cold filter plugging point exhibit reverse behaviors. However, triacetin has a lower melting point than methyl oleate, it is difficult to envisage the occurrence of cold filter plugging at that point due to separation. It is assumed that a cause of the higher cold filter plugging point was not made by separating solidified higher melting point materials, but because the higher concentration of triacetin raised the viscosity. Therefore, it is reasonable to conclude that the influence of triacetin on the cold filter plugging point is negligible.

\subsubsection{Oxidation stability}

In Fig. 5, the influence of changes in the triacetin concentration in the fuel mixture is shown on the oxidation stability. In the Rancimat test method, the oxidation stability is indicated by the time needed for the rapid increase in the electrical conductivity as an induction time. Compared with methyl oleate with its induction time of $1.2 \mathrm{~h}$, the higher the triacetin concentration, the longer the induction time. In particular, in fuel mixtures with a triacetin concentration more than $90 \mathrm{wt} \%$, a clear induction time was not detected because the rise in the conductivity was slowed to a large extent. Moreover, for measurements of triacetin on its own, almost no increase in the conductivity was observed even after $120 \mathrm{~h}$. From these lines of evidence, it is clear that triacetin has high oxidation stability and doesn't have negative effect on oxidation stability of BDF.

\subsubsection{Fuel properties of model BDF}

Table 1 shows the fuel characteristics of methyl oleate, triacetin (TA), and model fuel compared to the BDF standards of Kyoto, JASO, EU, and USA. Of these, the cetane number is the index of the auto-flash point of the fuel which has a strong relationship to the anti-knock properties in diesel engines. Moreover, the influence of the mixing of triacetin was very small on the flash point and even on the residual carbon fraction, and all values of standards were satisfied, except for density. The cetane number of the model BDF is 64.5 , and by mixing triacetin, the value for methyl oleate becomes lower than 86.3 . Thus, when the cetane number of mixture of FAME and triacetin is below the standard value, some 
addictives should be added to improve cetane number. From these results, it is clear that the effects of triacetin on these fuel properties are very small.

\subsection{BDF production using supercritical methyl acetate}

The manufacturing process of BDF using supercritical methyl acetate is shown in Fig. 6. In this process, the starting material of rapeseed oil is processed with supercritical methyl acetate at conditions of $350^{\circ} \mathrm{C}$ and $20 \mathrm{MPa}$, and the oil is converted to FAME and triacetin. The unreacted methyl acetate is removed from the products thereafter and can be reused. The reactants after the removal of the methyl acetate are a mixture of FAME and triacetin and are defined as BDF in this process. Therefore, theoretically an amount of BDF corresponding to $125 \mathrm{wt} \%$ of the oil can be derived. The actually recovered amount of BDF at $105 \%$ is probably short of the maximum recovery of $125 \%$ because of the high temperature breakdown of some unsaturated fatty acid methyl esters, but is higher than the maximum conventional recovery of BDF (100\%), when measured as FAME only.

Therefore, if the FAME and triacetin mixture derived in this process can be used as BDF, a big contribution to the effective use of resources can be expected. However, as the reactivity of triglycerides and methyl acetate is not very high and requires extreme reaction conditions $\left(350^{\circ} \mathrm{C}\right.$ and $\left.20 \mathrm{MPa}\right)$ to produce BDF in high yield, milder reaction conditions for the supercritical processing need to be investigated.

\section{Conclusion Remarks}

In this research, the use of methyl acetate as the reaction solvent was investigated in the manufacture process of BDF, producing FAME and triacetin from rapeseed oil with the aim of solving the problem of the by-product glycerol in the conventional processes. As a result, it became evident that the non-catalytic trans-esterification reaction between methyl acetate and triglycerides proceeding in the supercritical process could result in a high yield of FAME and triacetin. Moreover, it was clear that an esterification reaction between fatty acids and methyl acetate proceeded yielding FAME. 
Also, in order to investigate the fuel characteristics of triacetin, it was mixed with methyl oleate and the various fuel related characteristics of kinematic viscosity, low temperature pour point, and oxidation stability were studied for the first time ever. As a result, it became evident that the mixing of triacetin with FAME had favorable effects on the drop point and oxidation characteristics. Moreover, it was discovered that if a mixture ratio of FAME to triacetin of the order of 3:1 was used, where the triglyceride was completely converted, it had almost no adverse effects on the kinematic viscosity, cold filter plugging point, and flash point. However, the addition of triacetin lowered the cetane number. Therefore, by addition of some additives to improve cetane number, negative effect of triacetin on fuel properties can be dissolved.

If BDF is defined as a mixture of FAME and triacetin, the BDF recovery from supercritical processing of rapeseed oil with methyl acetate is $105 \mathrm{wt} \%$ compared with a theoretical maximum of 125 wt $\%$. This compares to the $100 \mathrm{wt} \%$ yield of BDF defined as FAME only in the conventional process. Therefore, it is evident that the supercritical methyl acetate method, which produces no glycerol as a by-product can be used effectively with limited resources.

\section{Acknowledgments}

This work has been done in NEDO "Development of Preparatory Basic Bioenergy Technologies" Project in FY2006-2007, for which the authors are highly acknowledged.

\section{References}

[1] Mittelbach M, Remschmidt C. Oil-pretreatment. In: Biodiesel. Vienna: Boersedruck Ges.m.b.H; 2004, p.44-46.

[2] Tomasevic AV, Marinkovic SSS. Methanolysis of used frying oil. Fuel Proc Technol 2003;81:1-6.

[3] Saka S, Kusdiana D. Biodiesel fuel from rapeseed oil as prepared in supercritical methanol. Fuel 2001;80:225-231.

[4] Kusdiana D, Saka S. Methyl esterification of free fatty acids of rapeseed oil as treated in supercritical methanol. J Chem Eng Jpn 2001;34:383-387. 
[5] Warabi Y, Kusdiana D, Saka S. Biodiesel fuel from vegetable oil by various supercritical alcohols. Appl Biochem Biotechnol 2004;115:793-801.

[6] Tabe A, Kusdiana D, Minami E, Saka S. Kinetics in transesterification of rapeseed oil by supercritical methanol treatment. In; Proc of the 2nd World Biomass Conf - Biomass for Energy, Ind and Climate Prot 2004, p.1553-1556.

[7] Imahara H, Minami E, Hari S, Saka S. Thermal stability of biodiesel in supercritical methanol. Fuel 2008;87:1-6.

[8] Cao W, Han H, Zhang J. Preparation of biodiesel from soybean oil using supercritical methanol and co-solvent. Fuel 2005;84:347-351.

[9] Han H, Cao W, Zhang J. Preparation of biodiesel from soybean oil using supercritical methanol and $\mathrm{CO}_{2}$ as co-solvent. Proc Biotechnol 2005;40:3148-3151.

[10] Kusdiana D, Saka S. Two-step preparation for catalyst-free biodiesel fuel production. Appl Biochem Biotechnol 2004;115:781-791.

[11] Johnson DT, Taconi KA. The glycerin glut: Options for the value-added conversion of crude glycerol resulting from biodiesel production. Environ Progress 2007;26:338-348.

[12] Fabbri D, Bevoni V, Notari M, Rivetti F. Properties of a potential biofuel obtained from soybean oil by transesterification with dimethyl carbonate. Fuel 2007;86:690-697.

[13] Xu Y, Du W, Liu D, Zeng J. A novel enzymatic route for biodiesel production from renewable oils in a solvent-free medium. Biotechnol Letters 2003;25:1239-1241.

[14] Riddick JA, Bunger WB. Methyl acetate. In: Organic solvents (third edition). New York: Wiley-Interscience; 1970, p. 270-271.

[15] Minami E, Saka S. Kinetics of hydrolysis and methyl esterification for biodiesel production in two-step supercritical methanol process. Fuel 2006;85:2479-2483.

[16] Kusdiana D, Saka S. Kinetics of transesterification in rapeseed oil to biodiesel fuel as treated in supercritical methanol. Fuel 2001;80:693-698.

[17] Kusdiana D, Saka S. New process for non-catalytic biodiesel production via hydrolysis and 
subsequent methyl esterification. In; Proc of the 2nd World Biomass Conf - Biomass for Energy, Ind and Climate Prot 2004, p.1484-1487.

[18] Knothe G, Steidley KR. Kinematic viscosity of biodiesel components (fatty acid alkyl esters) and related compounds at low temperatures. Fuel;2007;86:2560-2567.

[19] Candy L, Vaca-Garcia C, and Borredon E. Synthesis and characterization of oleic succinic anhydrides: Structure-property relations. J Am Oil Chem Soc 2005;82(4):271-277.

[20] Maryadele JO, Patricia EH, Cherie BK, Kristin JR. Triacetin. In: The merck index. New York: Merck \& Co., Inc; 2006, p.1649.

[21] Mittelbach M, Remschmidt C. Cold temperature properties. In: Biodiesel. Vienna: Boersedruck Ges.m.b.H; 2004, p.155-160. 


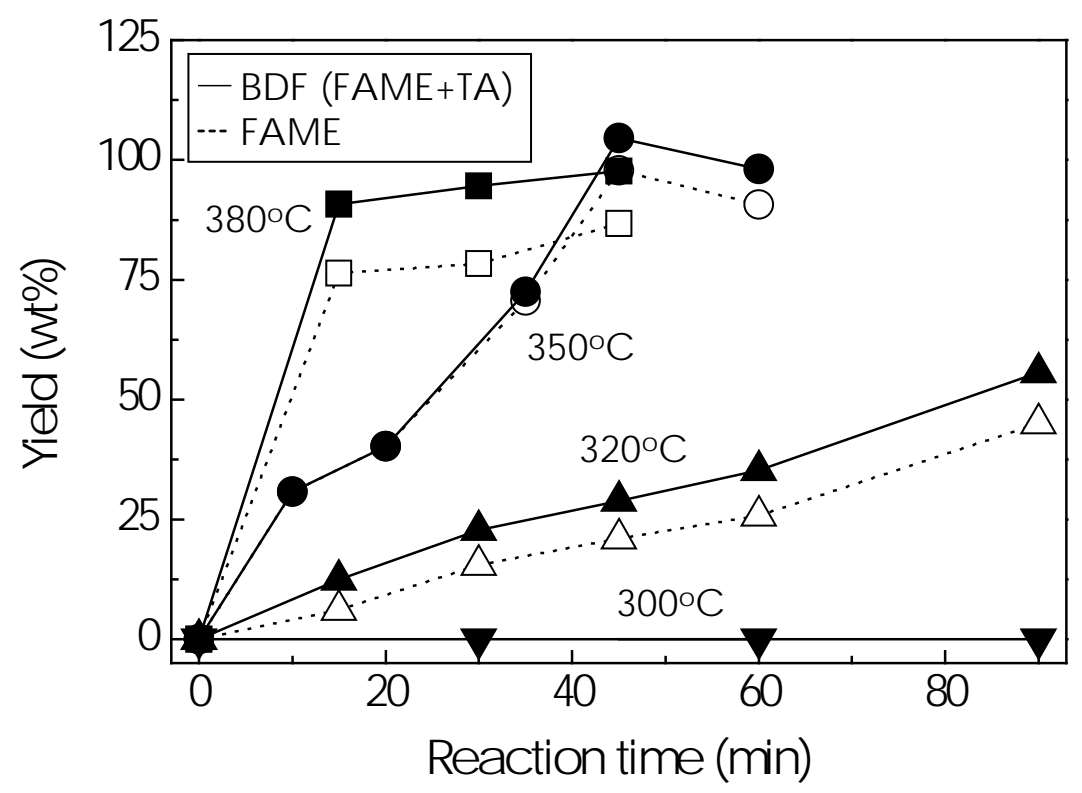

Fig. 1. Yields of FAME and BDF (FAME + TA) from rapeseed oil as treated in supercritical methyl acetate at various temperatures in 20MPa (methyl acetate/oil $=42 / 1(\mathrm{~mol} / \mathrm{mol})$ ). 


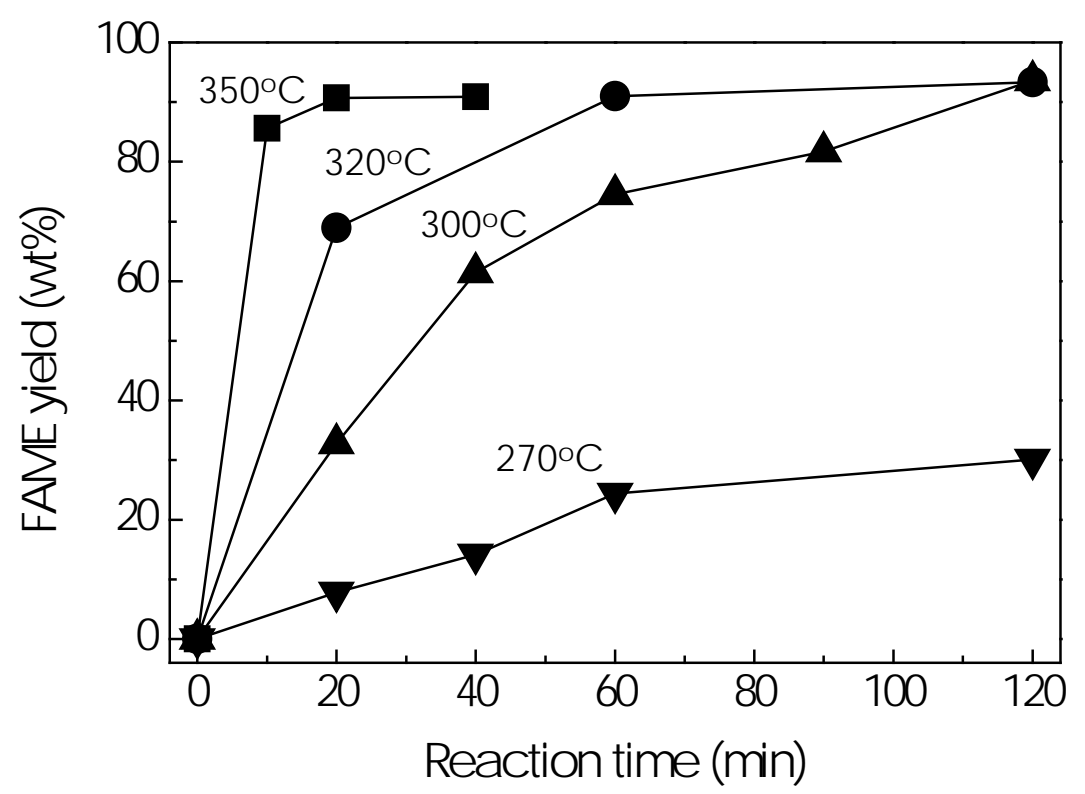

Fig. 2. Yield of FAME from oleic acid as treated in supercritical methyl acetate at various temperatures in 20MPa (methyl acetate/oleic acid = 14/1 (mol/mol)). 
Temperature $\left({ }^{\circ} \mathrm{C}\right)$

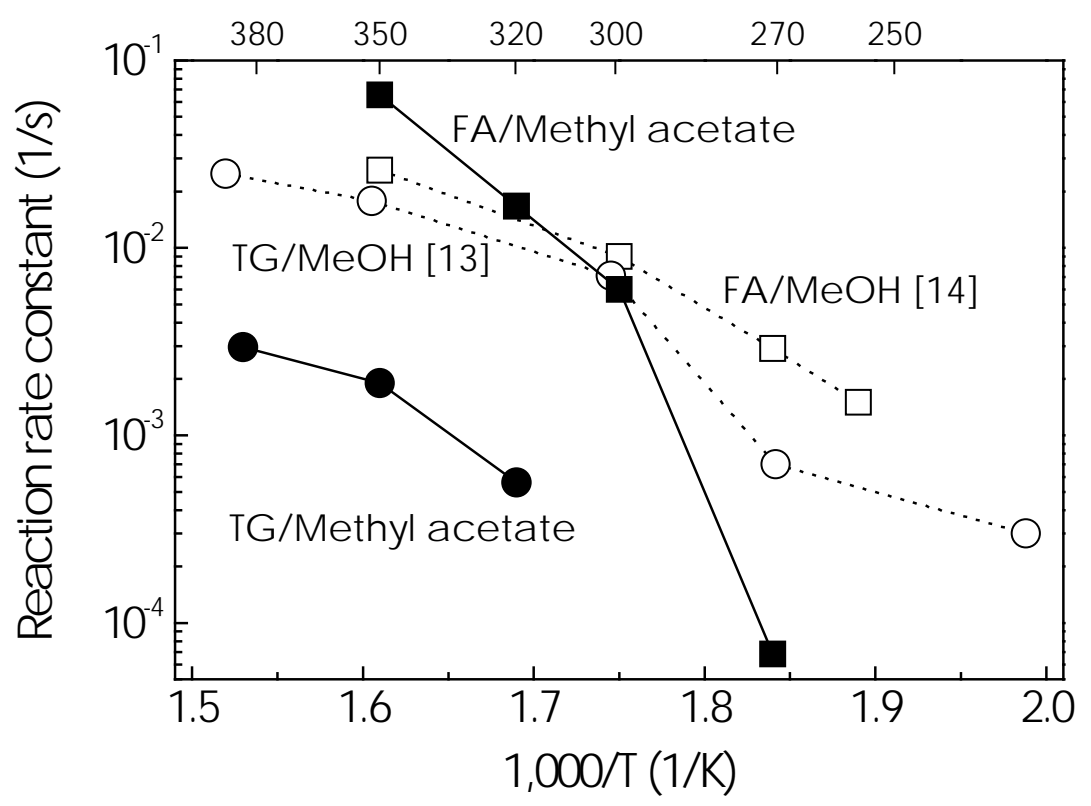

Fig. 3. Arrhenius plots for reaction rate constants on transesterification and esterification by supercritical methyl acetate at 20MPa. Different methods of calculation were adopted for each reactions. For a comparison, the results with methanolin batch-type reaction system are included [13,14]). 
(a) Kinematic viscosity at $40^{\circ} \mathrm{C}$

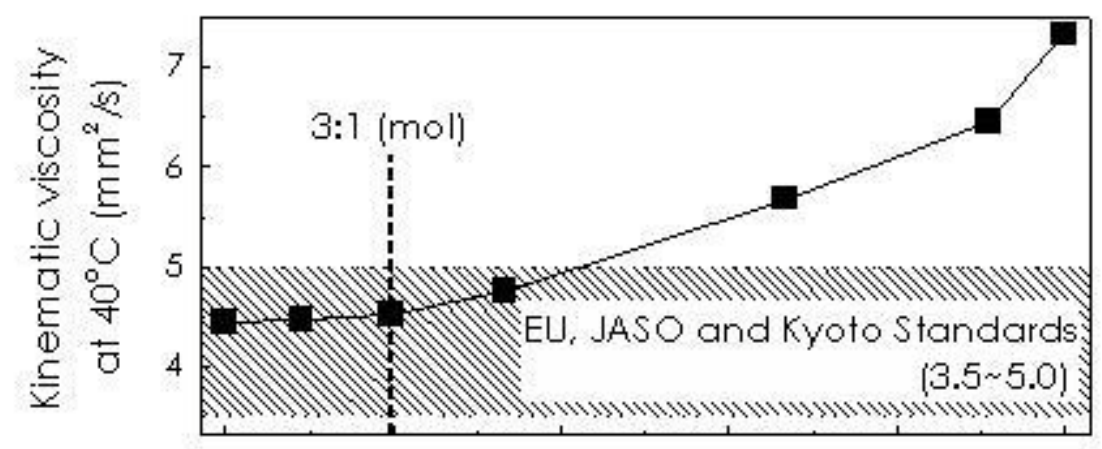

(b) Pour point

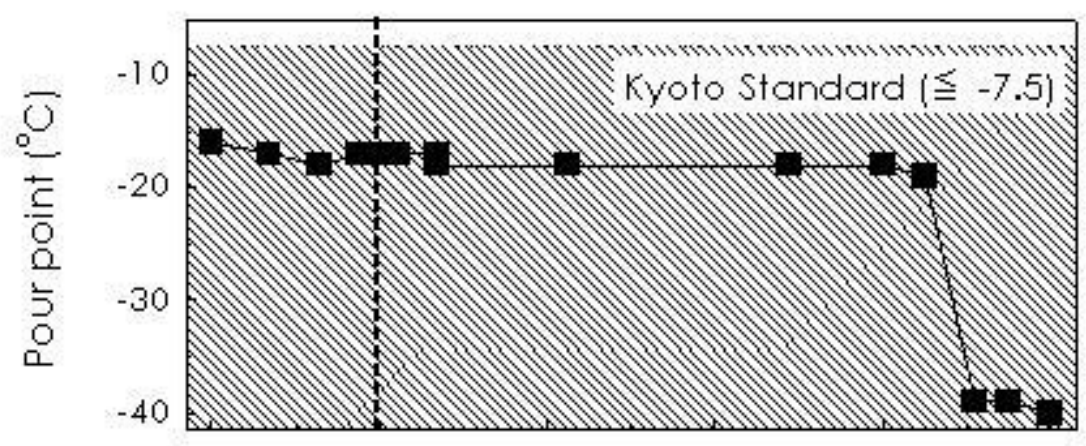

(c) Cold filter plugging point

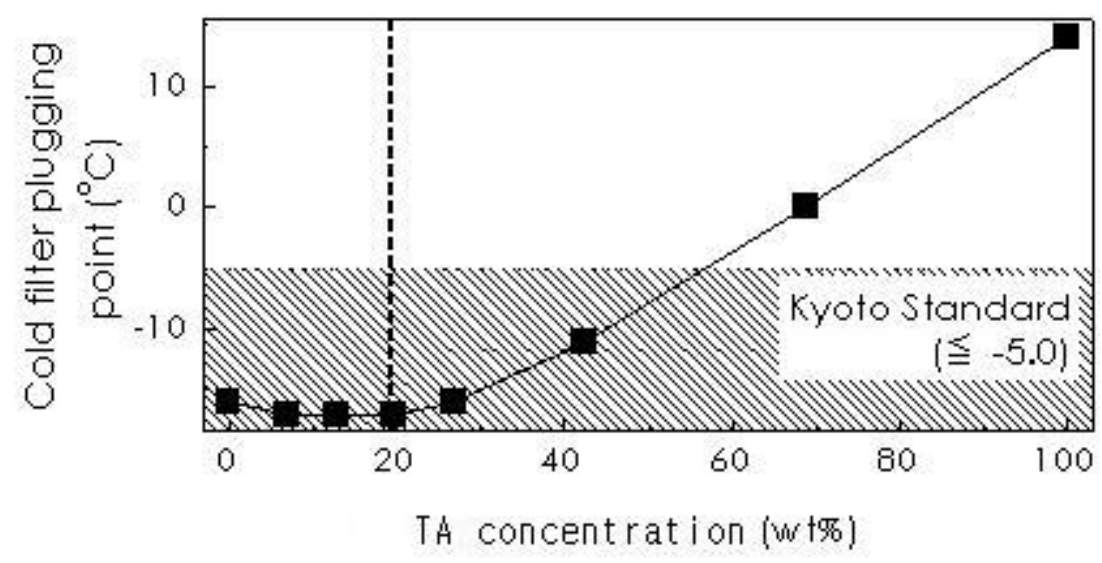

Fig. 4. Kinematic viscosity (a), pour point (b) and cold filter plugging point (c) of blends of TA in methyl oleate. The shaded area shows a range to satisfy the BDF standard, while the vertical dotted line the TA content in model BDF. 


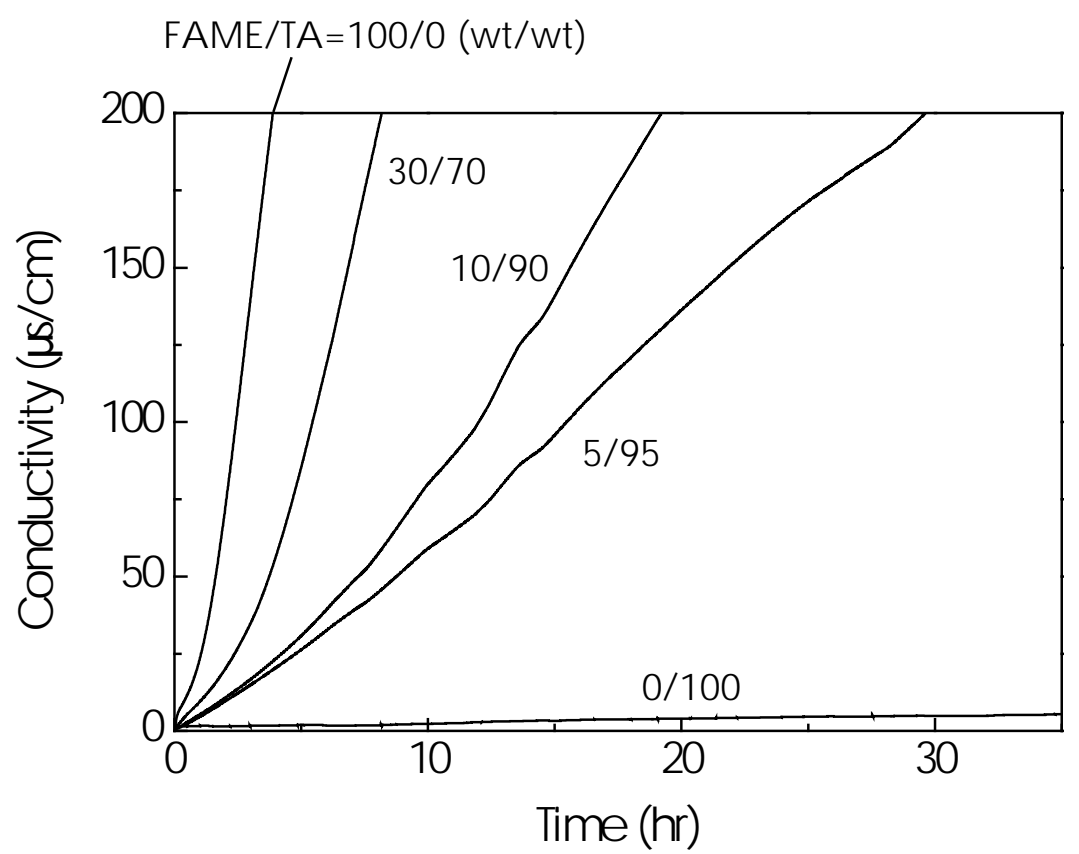

Fig. 5. Effect of TA content over its mixture with methyl oleate on oxidation stability. 


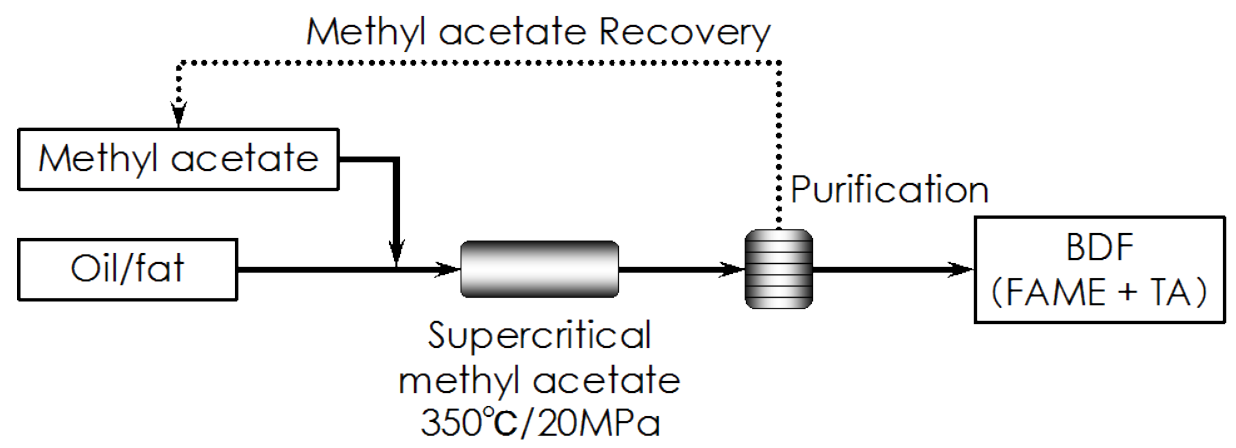

Fig. 6. Process for catalyst-free biodiesel production with supercritical methyl acetate. 
Table 1

Comparison of the fuel properties among methyl oleate, Triacetin (TA) and model BDF for established BDF standards

\begin{tabular}{|c|c|c|c|c|c|c|c|}
\hline \multirow{2}{*}{ Properties } & \multirow{2}{*}{ FAME } & \multirow{2}{*}{ TA } & \multirow{2}{*}{$\begin{array}{l}\text { Model } \\
\text { BDF* }\end{array}$} & \multicolumn{4}{|c|}{ BDF standards } \\
\hline & & & & Kyoto & JASO & EU & US \\
\hline Density at $15^{\circ} \mathrm{C}\left(\mathrm{kg} \mathrm{m}^{-3}\right)$ & 0.88 & 1.16 & 0.92 & $\begin{array}{c}0.86 \\
\sim 0.90\end{array}$ & $\begin{array}{l}0.86 \\
\sim 0.90\end{array}$ & $\begin{array}{l}0.86 \\
\sim 0.90\end{array}$ & - \\
\hline Cetane number & 86.3 & $\leqq 15$ & 64.5 & $\geqq 51$ & $\geqq 51$ & $\geqq 51$ & $\geqq 47$ \\
\hline Kinematic viscosity at $40^{\circ} \mathrm{C}\left(\mathrm{mm}^{2} \mathrm{~s}^{-1}\right)$ & 4.4 & 7.3 & 4.5 & $3.5 \sim 5.0$ & $3.5 \sim 5.0$ & $3.5 \sim 5.0$ & $1.9 \sim 6.0$ \\
\hline Pour point $\left({ }^{\circ} \mathrm{C}\right)$ & -16.0 & -40.0 & -18.0 & $\leqq-7.5$ & - & - & - \\
\hline Cold filter plugging point $\left({ }^{\circ} \mathrm{C}\right)$ & -16.0 & 13.5 & -17.0 & $\leqq-5.0$ & - & - & - \\
\hline Flash point $\left({ }^{\circ} \mathrm{C}\right)$ & 170.5 & 158.5 & 154.5 & $\geqq 100$ & $\geqq 120$ & $\geqq 101$ & $\geqq 130$ \\
\hline $100 \%$ Carbon residue (wt\%) & 0.02 & 0.01 & 0.03 & $\begin{array}{l}\leqq 0.30 \\
(10 \%)\end{array}$ & $\begin{array}{l}\leqq 0.30 \\
(10 \%)\end{array}$ & $\begin{array}{l}\leqq 0.30 \\
(10 \%)\end{array}$ & $\leqq 0.05$ \\
\hline
\end{tabular}

$*$ Methyl oleate $/ \mathrm{TA}=3: 1(\mathrm{~mol} / \mathrm{mol})$ 